\title{
Duodenal Metastasis from Renal Cell Carcinoma presenting as Gastrointestinal Bleed
}

\author{
Mohamad Ashraf Teli, M.D., ${ }^{1}$ Omar Javid Shah, M.S., ${ }^{2}$ Aleem M Jan, M.D., ${ }^{3}$ Nazir A Khan, M.D' \\ Departments of Radiation Oncology, Surgical Gastroenterology, and Clinical Haematology, Sher-i-Kashmir Institute of Medical \\ Sciences, Srinagar-190011, Kashmir, India
}

\section{A B S T R A C T}

\begin{abstract}
Malignant causes account for 1-4\% of upper gastrointestinal bleeding (Gl-bleed). In absence of widespread nodal and visceral metastatic disease, isolated duodenal metastasis from renal cell carcinoma (RCC) is very rare. Consequently, gastrointestinal bleeding from renal cell carcinoma metastases is an infrequent and often un-recognized manifestation of this disease.

Here, we describe case of a 52 year-old man in whom metastasis arising from renal cell carcinoma developed in the duodenum 8 years after nephrectomy as the first relapse. The patient presented with severe anemia due to occult Gl bleed. The diagnosis was confirmed by endoscopic biopsy and immuno-histochemistry (IHC).Palliative local resection of the tumor was attempted, however, patient had progression of the disease and developed liver metastasis with pleural effusion and succumbed to his disease.

Since, late recurrence/metastasis is characteristic of renal cell carcinoma, careful long-term follow-up is needed to pick up an early relapse. To our knowledge, this is the 20 th case of duodenal metastasis from RCC and the first case from Kashmir valley of Indian sub-continent reported in literature. JMS 2012;15(1):65-68.
\end{abstract}

KeyWords: Duodenal metastasis, renal cell carcinoma, Gl bleed

Renal cell carcinoma constitutes 3\% of all adult malignancies and often presents insidiously with vague abdominal symptoms. It has a variable natural course and metastatic involvement of the lung, lymph nodes, liver, bone, adrenal glands, kidney, brain, heart, spleen, intestine, and skin is usually seen in descending order of frequency. However, the duodenum is an uncommon site for metastasis from renal cell carcinoma. Consequently, diagnosis and an appropriate treatment are often delayed because of rarity of

\section{Correspondence:}

Dr. Mohmad Ashraf Teli

Additional Professor,

Department of Radiation Oncology, Sher-i-Kashmir Institute of

Medical Sciences, Soura, Srinagar-190011, Kashmir-India

E-Mail:-ashrafteli2004@yahoo.com this type of metastatic involvement. Thorough endoscopic evaluation of the upper small intestine and a high index of suspicion are vital for correct diagnosis and appropriate management of this type of metastatic involvement.

\section{Case Presentation}

RT-500/02, a 52 year old Kashmiri (Asian) male, an exsmoker, presented with complains of intermittent painless hematuria of 4 months duration. There was no history of fever, spasmodic pain, breathlessness or bleeding tendencies from other sites. His general physical examination was normal and there was no lymphadenopathy. His chest, cardiovascular and abdominal examination did not reveal any abnormality. On investigations, his haemogram, biochemical parameters and X-ray of chest were normal. His urine 
examination revealed full field RBCs and abdominal ultrasound examination revealed an iso-echoic right renal mass. A contrast CT scan examination conducted in May, 2000 revealed an iso-dense moderately enhancing mass replacing upper $2 / 3 \mathrm{rd}$ of right kidney with early changes of central necrosis. Peri-renal fascia and inferior vena-cava were normal. There was no regional lymphadenopathy (Figure 1). The patient underwent right radical nephrectomy.

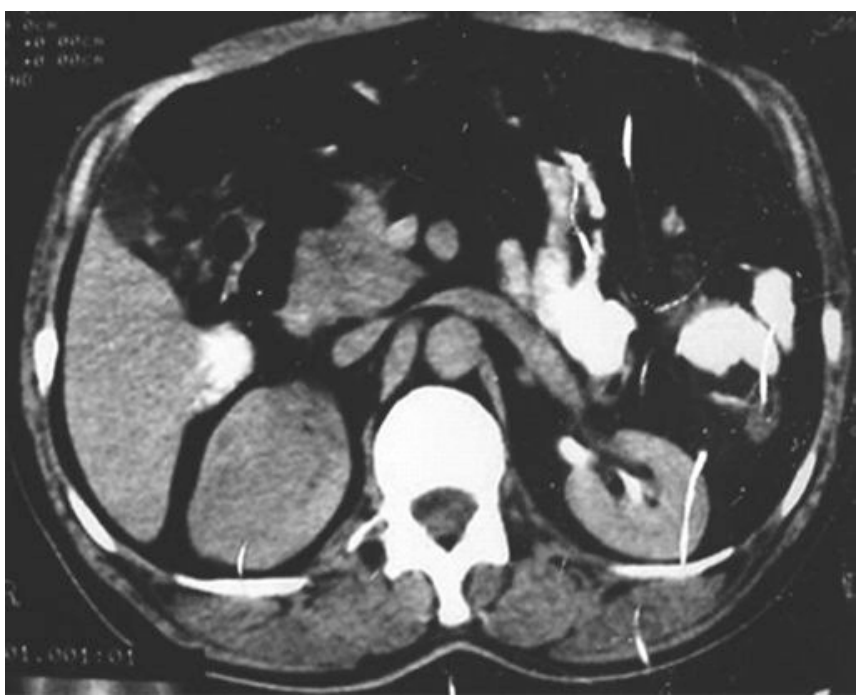

FIGURE 1: CT scan cut showing right renal tumor

Operative findings were consistent with T2, N0 status. Histopathology of the specimen revealed features of renal cell carcinoma with intact capsule without any vascular and/or lymphatic infiltration. Metastatic work-up confirmed M0 status and patient was put on regular follow-up at 3-6 monthly intervals with X-ray chest, urine examination, abdominal ultrasound and bone scan examinations. Patient remained disease free till August, 2008 when he presented with severe anemia with hemoglobin value of $4 \mathrm{gms} / \mathrm{dl}$. He was admitted for evaluation and supportive care. His bone scan, X-ray chest, an ultra-sound examination of abdomen/ pelvis and bone marrow examination did not reveal any evidence of metastatic disease. An upper GI endoscopy performed revealed a bleeding duodenal mass (deposit) with clot and crust on surface. Blind biopsy was deferred as there was apprehension of aggravating the GI bleed. A contrast enhanced CT scan of abdomen and pelvis confirmed the presence of duodenal tumor (Figures 2a \& 2b).Patient was operated upon in September, 2008. Abdomen was opened by a midline incision. Adhenolysis done after duodenal kocherization and duodenotomy was performed. An ulceroproliferative deposit (6 x $5 \mathrm{cms}$ ) was seen arising from anteromedial aspect of the second part of duodenum in juxtapapillary region. Pancrease was felt free. Identification of the papilla was done through supraduodenal longitudinal choledochotomy and a local excision of the tumor was performed. Rest of laparotomy was normal. Biopsy of the specimen gave possibilities of Yolk sac tumor / Gastrointestinal stromal tumor(GIST).Immuno-histochemistry (IHC) with AFP, HMB-45, and CD 117 was suggested. AFP IHC was equivocal; HMB-45 IHC was negative and so was the IHC for CD 117. However, IHC for cytokeratin 18 and cytokeratin 8 were positive establishing the diagnosis of renal cell carcinoma. (Figure 3a). Patient was given option of interferon/interleukin-2 and other targeted therapy but he refused. He remained stable till last week of January, 2009 when his GI bleed recurred. Patient was admitted in Accident \& Emergency unit and managed conservatively. CT scan demonstrated residual metastasis in duodenum and liver metastasis(Figure 3b). As a last resort palliative radiotherapy to duodenal metastatic tumor was planned but patient refused and was discharged on request-(died at home one week later).

\section{Discussion}

Renal cell carcinoma represents 3\% of all adult malignancies. It has an un-predictable behavior and varied range of clinical manifestations. Approximately, 25-30\% of patients

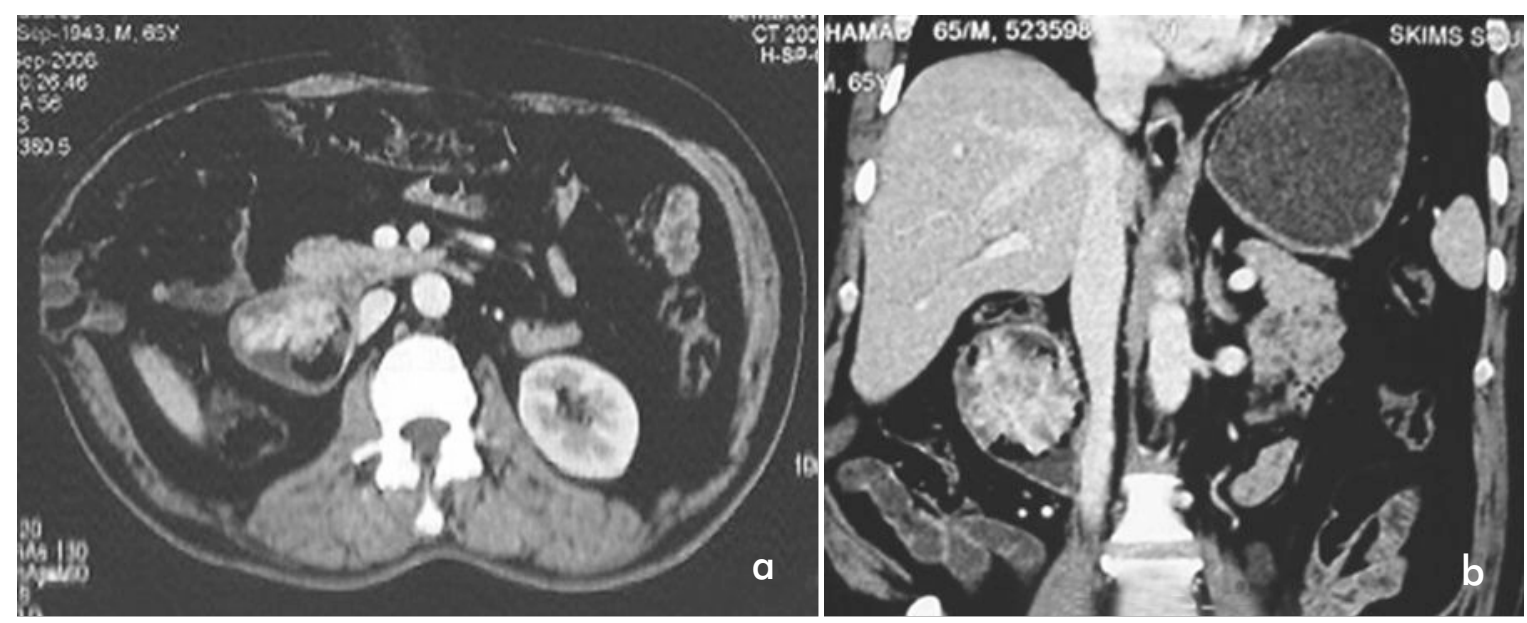

FIGURE 2(a \& b): CT scan cuts showing a big duodenal metastasis 

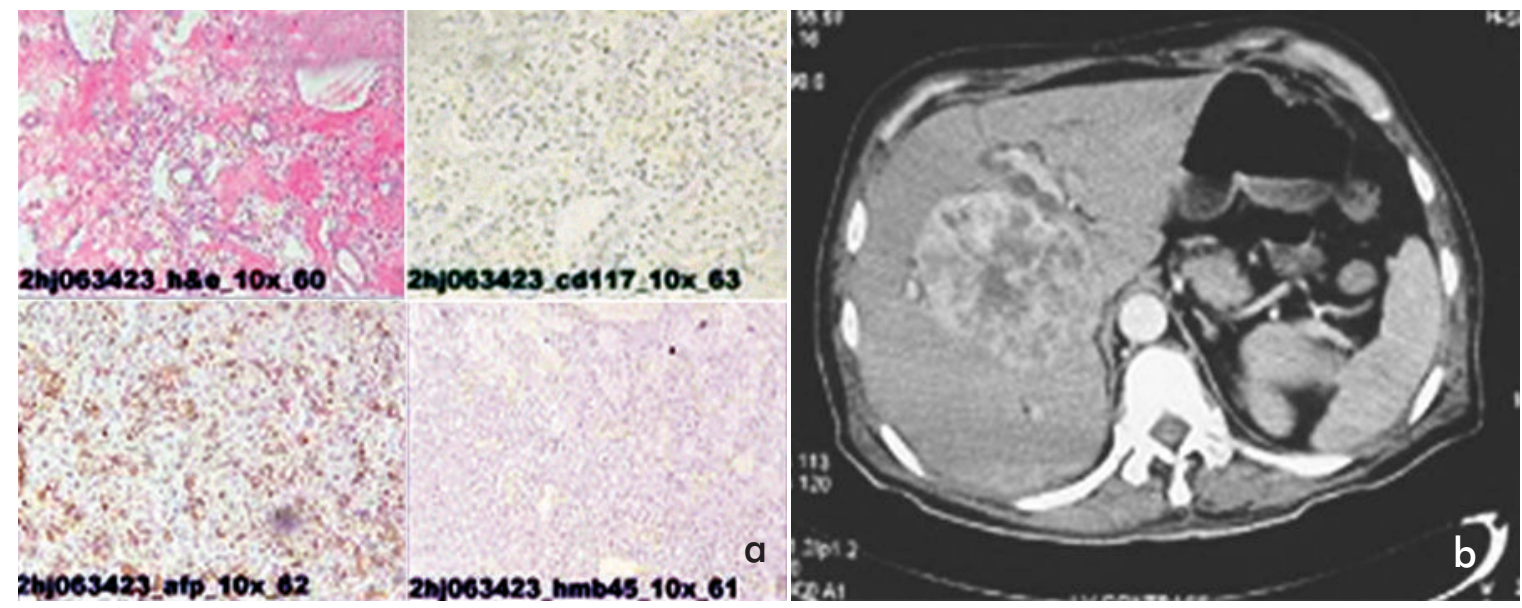

FIGURE 3: (a) H\&E and IHC slides positive for cytokeratin 18 \& 8; (b) CT scan cut showing huge liver metastasis

present with metastatic disease and $30-50 \%$ patients with local disease develop metastases during the course of their illness with the lungs, the liver, and the bones, the commonest sites of involvement. Overall, malignant causes of upper gastrointestinal bleeding account for $1-4 \%$ of cases. Autopsy series have revealed small bowel involvement by metastatic tumors in $2 \%$ cases. Renal cell carcinoma accounts for $4-7.1 \%$ involvement in all metastatic tumors to small intestine. Renal cell carcinoma metastising to pancreas and small intestine is an uncommon presentation. Morever, isolated duodenal metastasis from RCC is a very rare event ${ }^{1,2}$ and to our knowledge 19 such cases have been reported till $2006 .{ }^{3} \mathrm{~A}$ vast majority of these patients have right sided renal tumors. The present index case had also undergone nephrectomy for his right sided RCC. Metastatic lesions of the duodenum are most frequently located in the peri-ampullary region or the duodenal bulb. ${ }^{4}$ On endoscopy the lesion is often seen as a sub-mucosal mass with ulceration of the tip, multiple nodules of varying sizes or raised plaques. In the present case the metastatic lesion was seen as a $6 \times 5 \mathrm{~cm}$ ulceroproliferative lesion in the 2 nd part of duodenum (Juxtapapillary). The patients commonly present with gastrointestinal bleeding or intestinal obstruction. ${ }^{6}$ Since, malignant causes of upper GI bleed are not frequent and as tumors of small intestine are un-common (0.35\%) symptoms are non-specific and diagnosis may get delayed. ${ }^{7}$ Our patient presented with severe anemia associated with occult GI bleed and at his terminal stage he developed metastatic liver involvement and pleural effusion as well. Majority of RCC patients are found to have metastasis within a year or two after nephrectomy though cases metastising to duodenum/pancreas have been reported after 13 and 27 years latency period. ${ }^{3,89}$ In the index case duodenal metastasis developed 8 years after nephrectomy showing thereby the quiescent and very un-predictable natural history of the disease. A prolonged latent interval from nephrectomy to metastatic event seems to confer a better prognosis. ${ }^{9}$ However, this did not happen in our patient in whom the disease behaved very aggressively with metastatic involvement of liver and pleural effusion resulting in a rapid downhill course. Treatment options in a case of RCC metastasis depend upon the extent and location of the lesion. In the majority of reported cases of duodenal metastasis, metastatectomy was performed. ${ }^{10}$ In the index case palliative metastatectomy was performed but fast re-growth of the residual disease was noticed with later fulminant wide spread metastatic disease. We did not attempt arterial embolization in our patient though it has been tried in such presentation. Patient was given option of interferon/interleukin-2/sunitinib but he refused. It is known that treatment even with these modalities yields poor survival in patients with wide spread metastatic disease with average survival of about 4 months and only $10 \%$ of these survive for one year. ${ }^{11}$

\section{Conclusion}

Gastrointestinal bleeding from duodenal metastasis may present with frank hematemesis or signs of occult blood loss or intestinal obstruction. Due to its rarity, duodenal metastasis in RCC is often not suspected leading to delayed diagnosis and clinical deterioration of patient. The present report highlights the importance of investigating patients of RCC presenting with any gastro-intestinal tract manifestations for metastasis particularly in pancreatico-duodenal areas. A complete evaluation, especially endoscopic examination and biopsy, needs to be carried out in such patients. Awareness of this type of presentation and a high index of suspicion on the part of treating physician/oncologist and pathologist would help in making a proper diagnosis and institution of an early treatment. ${ }^{12}$

\section{References}

1. Chang WT, Chai CY, Lee KT. Unusual upper gastrointestinal bleeding due to late metastasis from renal cell carcinoma - A case report. Kaohsiung J Med Sci 2004; 20(3):137-41. 
2. Gareth J Sadler, Mark R Anderson, Mark S Moss, and Paul G Wilson. Metastases from renal cell carcinoma presenting as gastrointestinal bleeding: two case reports and a review of the literature. BMC Gastroenterology 2007; 7:4.

3. Naoki Segawa, Hirohito Azuma, Yoshihiko Nakanishi, Yutaka Hiraike, Hironori Kanehara, Motomu Tsuji, Yoji Katsuoka. Pancreatic and duodenal metastases from renal cell carcinoma 13 years after radical nephrectomy: a case report. Hinyokika Kiyo 2006;52 (11):845-50 [17176866 (P,S,G,E,B)]

4. Pavlakis GM, Sakorafas GH, Anagnostopoulos, GK. Intestinal Metastases from Renal cell carcinoma: A Rare Cause of Intestinal obstruction and Bleeding. Mt SinaiJ Med 2004;71:127-30.

5. Hsu CC, Chen JJ, Changchein CS. Endoscopic features of metastatic tumours in upper gastrointestinal tract. Endoscopy 1996;28:249-53.

6. SK Toh, JE Hale. Late presentation of a solitary metastasis of renal cell carcinoma as an obstructive duodenal mass. Postgrad Med J 1996;72:178-79.

7. Loualidi A, Spooren PFMJ, Grubben MJAL, Bloomjous CEM, Goey SH. Duodenal metastasis: an un-common cause of occult small intestinal bleeding. Neth JMed 2004;62(6):201-5.

8. Merino C, Moles JR, Rodrigo A, Fernando J, Garcia J, Primo J, Albert A, Arago M et al. Uncommon etiology of gastrointestinal bleeding: Duodenal metastases from renal cell carcinoma. Gastroenterol Hepatol 2005; 28(4): 221-4.

9. Faure JP, Tuech JJ, Richer JP, Pessaux P, Arnand JP, Cautier M. Pancreatic metastasis of renal cell carcinoma: presentation, treatment and survival. Urol 2001;65(1):20-22.

10. Hashimoto M, Miura Y, Matsuda M, Watanabe G. Concomitant duodenal and pancreatic metastases from renal cell carcinoma: report of a case. Surg Today 2001; 31(2):180-3.

11. Motzer RJ, Hutson TE, Tomczak P, et al. Sunitinib versus interferon alfa in metastatic renal-cell carcinoma. NEngl J Med 2007;356:115-24.

12. Tuech JJ, Pessaux P, Chautard D, Rouge C, Binelli C, Bergamaschi R, Arnand JP. Results of duodenopancreatectomy for solitary pancreatic metastasis from renal cell carcinoma. J Hepatobilliary Pancrteat Surg 1999; 6(4):396-8. 